\title{
EL CONCEPTO DE HOMBRE Y LA ÉTICA
}

Carlos de la Isla*

\section{Cuando Heidegger justifica la pre-} gunta que pregunta sobre el sentido del ser insiste en que el ser es lo más cercano pero al mismo tiempo lo más lejano, es lo más claro pero al mismo tiempo lo más obscuro, es lo más evidente pero permanece encubierto. Igualmente parece legítimo plantear la pregunta que pregunta sobre el sentido del hombre; porque, ¿qué más próximo al hombre que el ser de sí mismo? ¿Qué mayor evidencia de su pensamiento que cuando se piensa? ¿Qué mayor claridad de sus goces y dolores que cuando goza y se duele? Y, sin embargo, cada hombre para sí mismo y para cada uno de los otros constituye una cercanía lejana, una claridad obscura, una evidencia encubierta. Es trascendental en el sentido más fuerte plantear y replantear la pregunta sobre lo que el hombre es porque, como bien dice Kant, el filósofo de Königsberg, sólo cuando sabemos qué es el hombre podemos saber qué puede conocer, qué debe hacer y qué puede esperar.

De hecho toda la filosofía del gran filósofo alemán es una glosa del concepto que tiene del hombre: el extraordinario poder de la razón da origen a su principal tesis sobre la Crítica de la razón pura y también a la Crítica de la razón práctica; sus imperativos de la Metafísica de las costumbres tienen como fundamento la dignidad del hombre que lo constituye en fin en sí mimo; su fe en la razón es la fuerte premisa de la Paz perpetua; y su percepción sobre la inmortalidad del alma

\footnotetext{
* Departamento Académico de Estudios Generales, ITAM.
} 
(postulado de la Razón práctica) permite contestar la pregunta ¿qué puedo esperar?

Con mucha razón también Sócrates insiste en la importancia del 'conócete a ti mismo'; porque si conoces quién eres sabrás qué puedes, qué debes y conocerás el inicio y el fin de tu camino. Así, de la concepción de hombre del Platón socrático se deriva su teoría del conocimiento (el alma que posee todas las ideas queda encarcelada en la obscuridad del cuerpo), pero también se siguen la ética y la política: el alma debe guiar y controlar al cuerpo y la razón a los apetitos; el rey filósofo debe gobernar porque conoce la Verdad y el Bien y por tanto conoce y quiere lo que es bueno para la pólis.

Tal vez el ejemplo más impresionante sobre la relación entre el concepto de hombre y la política es el que ofrece Hobbes, quien asegura que entre el lobo y el hombre existe un parentesco en primer grado. Los hombres luchan entre sí como lobos y, si se les deja sueltos (en estado natural) se destruirán inevitablemente; por lo tanto, es necesario atarlos al yugo del soberano. Deben ceder todos sus derechos al Príncipe para que éste posea un poder absoluto y pueda hacer posible la convivencia y subsistencia de los hombres-lobos.

Como se sabe, éste es el fundamento de la monarquía absoluta, de ese poder total encarnado en un príncipe que podrá "cometer hasta iniquidades pero nunca injusticias". De este razonamiento resulta la legitimación de la arbitrariedad y de la violencia que han ejercido los regímenes totalitarios y monarquías absolutistas. Es increíble que regímenes políticos tan crueles y perversos, que tan graves daños han causado a la sociedad, en buena parte se deriven de esa falsa concepción del hombre. De la misma idea nace la ética de la entera sumisión y obediencia ciega al poder del Estado.

Toda la cosmovisión liberal tiene no sólo su punto de partida sino también su entera gestación en el concepto que sustenta sobre el hombre. El liberalismo defiende la soberanía total: "en lo que sólo a sí concierne el individuo de hecho tiene libertad absoluta. Sobre sí mismo, su cuerpo y su espíritu el individuo es soberano", dice J. S. Mill. Si es soberano su libertad no tiene más límites que las sobera- 
nías de los demás. La ética está definida por la utilidad, el placer y la satisfacción del soberano. La economía debe consistir en el libre intercambio de bienes, porque nadie mejor que cada individuo para saber qué hacer con lo que tiene (libre mercado). Y la política debe limitarse a custodiar la soberanía de los ciudadanos y de la nación.

En la propia concepción del materialismo dialéctico y del materialismo histórico subyace un concepto definido de hombre. Aunque Marx no aceptaba la existencia de un 'hombre' universal, abstracto y vacío, sino la realidad de hombres hechos de su historia, de las relaciones materiales de su existencia, finalmente este ser singular, hecho realidad con otros hombres es el actor principal del proceso histórico en el que debe ser liberado del mundo de la necesidad para hacer posible su ingreso al reino de la libertad.

El propio Nietzsche, que ataca implacablemente a la razón, justifica con coherencia impecable la exaltación del superhombre a partir del concepto que tiene del hombre: una vez celebrado el supuesto entierro de Dios queda el hombre liberado para desarrollar toda la musculatura de su animalidad. Semejante coherencia se encuentra también en la concepción de A. Comte: si no existe otro dios aparte del hombre, tiene sentido el proyecto arquitectónico del gran templo que venere a la diosa humanidad.

Los ejemplos se pueden extender a todas las cosmovisiones, a todos los sistemas filosóficos; aún las estructuras teocráticas tienen como piedra de sustento explícito o implícito el concepto del hombre.

Resulta angustioso y desconcertante que existan percepciones y concepciones tan diferentes y hasta contrarias y contradictorias sobre esa misma y única realidad llamada hombre. Esto puede significar la limitación y obstáculos del conocimiento humano, pero más bien significa substancialmente la profundidad inabarcable, misteriosa, inconmesurable de lo que el hombre es.

Un relativista diría que el concepto del hombre es relativo y que desde esta perspectiva de la relatividad todas las percepciones son correctas. Pero cuando se trata del ser del hombre: o el intelecto dice lo que el hombre es y así nos dice la verdad del hombre, o nos dice qué 
es lo que el hombre no es y así pronuncia la mentira sobre hombre. Lo contrario sería ofender el principio de no contradicción, que significa la caída estrepitosa en el nihilismo.

Es legítimo por tanto afirmar que muchas concepciones sobre lo que el hombre es son falsas y los edificios ideológicos construidos sobre ese soporte son frágiles y deleznables. El análisis de las distintas concepciones antropológicas sería un apasionante y muy provechoso trabajo de investigación filosófica especializada. Aquí solamente se señalan algunas visiones que parecen obviedades sobre lo que el hombre no es y una reflexión sobre matices y manifestaciones que expresa el hombre de su propio ser.

La idea de Dios que aparece en las principales culturas significa una "realidad en sí y por sí solo idéntica a sí misma en la unicidad de su forma" (Platón); un "Ser que existe por sí mismo cuya esencia es ser" (Aristóteles). Si se toma en serio la idea de Dios, es obvio que el hombre, por el solo hecho de tener madre, no es Dios. Y en cuanto a "la muerte y el entierro de Dios", no pasa de ser una metáfora apasionada de Nietzsche que quiere convertir al superhombre en bestialidad omnipotente.

136 En cuanto al parentesco del hombre con el lobo del que habla Hobbes, ya se ha demostrado con evidencia científica que la violencia no proviene de herencia genética, sino que principalmente es el resultado de un medio ambiente agresivo y violento, como se muestra en el círculo vicioso de las generaciones perversas: la injusticia social corrupta genera el odio, el odio genera violencia, la violencia genera ingobernabilidad, ésta genera armas represivas que emplean los recursos destinados para la salud, la educación, el desarrollo humano, y todo esto agudiza la injusticia, el odio, la violencia... Es importante la distinción: si el hombre es violento por razones genéticas, entonces sí se justifica la jaula del absolutismo político, pero si el hombre se hace violento por el medio, la solución consistirá en romper ese círculo de las generaciones perversas y substituirlo por el círculo virtuoso que se inicia en el bien común o justicia social y en la educación para la paz. 
La soberanía del hombre que el liberalismo coloca como cimiento de su cosmovisión es también muy cuestionable: la soberanía tomada en serio es sinónimo de absolutez, de autosuficiencia, y no hay nada más evidente en el ser del hombre que lo opuesto a tal soberanía: El hombre tiene una dependencia ontológica; su ser, su existencia, son evidentemente dados. El genoma humano va abriendo cada día más las pantallas de las imposiciones, limitaciones, y propensiones genéticas. ¿Quién puede negar la carga, el peso de su alteridad? ¿Hasta dónde avanza la alteridad y dónde empieza la mismidad? ¡Qué difícil es, a veces, rechazar el determinismo social! ¡La existencia hecha de relaciones materiales, sociales, políticas, culturales! Con razón dice el viejo proverbio árabe: "Los hombres se parecen más a su tiempo que a sus padres." Por eso la mentada soberanía se reduce de hecho a la trabajosa libertad que avanza con esfuerzo sobre la inevitabilidad.

Estas concepciones sobre el hombre, que con claridad meridiana se muestran falsas, no pasarían de ser meros errores del conocimiento o problemas gnoseológicos, pero los graves conflictos se inician cuando estas concepciones sobre el hombre se proyectan a la ética, a los quehaceres y deberes del hombre.

Es falsa, por tanto, la ética de la obediencia ciega, del sometimiento total, de la sumisión a la ley que expresa la voluntad del soberano, porque se deriva del falso concepto del hombre como lobo del hombre. Es falsa la ética que otorga al hombre libertad infinita y omnipotencia, porque el hombre no es Dios aunque ha sido su pasión prometeica llegar a ser Dios. Falsa y peligrosa es también la ética de un liberalismo extremo, utilitarista, hedonista, de todas las libertades y de todos los caprichos, porque se funda en una soberanía legitimadora que el hombre no tiene. Se cree y se siente como Señor del universo, maneja una autonomía en la que él es su propia ley y él es su mundo. Es la ética del egocentrismo, de la exaltación del yo hasta convertirlo en objeto único de veneración; es la egolatría como sistema de vida.

Ética falsa es ésta, pero se ha impuesto como la práctica cotidiana predominante en la sociedad contemporánea: el político busca apasionadamente y por todos los medios su poder personal. La sociedad y 
el propio partido le interesan como plataforma de conveniencia; las decisiones, aún las más trascendentes, de carácter nacional e internacional, las toma de acuerdo a sus intereses de popularidad y de captación de votos. El profesionista ejerce sus habilidades bajo el cálculo exclusivo de sus beneficios. Si el necesitado de su especialización no puede llegar a la altura del precio estipulado de sus 'servicios' peor para él. El altruismo, la responsabilidad social, la justicia conmutativa son costumbres piadosas de un pasado fuera de moda.

En las relaciones humanas, incluidas las matrimoniales, predomina también el criterio egolátrico-hedonista. La proximidad y cercanía se definen con criterio de utilidad y conveniencia. El aprecio se otorga cuando y mientras dura el placer de apreciar. El afecto, la amistad, el amor que no llevan en sí mismos el placer de sentirlos son idealidades románticas y cursis para nuestro pragmático mundo postmoderno. La educación es concebida como el arte (a veces la magia) de hacer personas útiles, productivas y productoras de beneficios y bienestares. El éxito de la educación se mide por el alto precio de las contrataciones, es decir, por el valor de cambio en el mercado. Los estudiantes estudian lo que 'sirve', lo que es 'útil', lo que podrá venderse para cobrar caro el oficio profesional para la producción del placer y del dinero. La formación integral, estética, intelectual con responsabilidad social, el desarrollo de la personalidad en la que la inteligencia, la voluntad, el carácter, la sensibilidad, la dignidad del ser personal sean lo más importante, resulta no sólo irrelevante sino un estorbo para el logro del 'éxito'.

\section{La ética del hombre humano}

La eticidad no es otra cosa que la orientación o prescripción del desarrollo de la humanidad en todas sus dimensiones; por eso su fin trascendental es el aprecio e impulso del ser humano en cuanto humano. Cuando Martin Heidegger en su carta sobre el humanismo inicia con gran precisión el análisis del término humanitas señala que 
los grandes griegos enfatizaron las dimensiones racional y social del hombre. Después de los griegos la filosofía siguió el camino de la animalitas, dando lugar a la gran bifurcación: humanitas y animalitas. La humanidad es lo que hace al hombre humano, y aquí su relación con la ética que, como se dijo, se propone el aprecio y crecimiento del hombre en cuanto humano.

La idea universal de esencia se refiere a lo necesario del ser, a lo que hace que algo sea tal, a lo indispensable que constituye lo único y diferente, aquello que si se pone 'es' y si se quita 'no es'. En este sentido de esencia se entienden algunas construcciones de la humanidad del hombre humano: La inteligencia es una construcción esencial de lo que se dice ser humano. Es una potencia con el poder de leer la interioridad del ser, la intimidad del ser. Los sentidos, los maravillosos sentidos, lectores de la animalitas, leen la exterioridad, la corteza del ser. La visión del ojo es la lectura del color, de los pliegues, de las formas que envuelven la esencia del ser de los seres. La vista puede percibir el tamaño, las formas, los movimientos, el colorido de una mujer hermosa, pero nada nos puede decir de su inteligencia, de su voluntad, de su sensibilidad, ni siquiera de su belleza. La inteligencia penetra la exterioridad para leer la interioridad: sus pensamientos, si piensa; sus amores, si ama; sus creaciones, si crea... Sólo la inteligencia puede leer el ser personal, porque es racional, social y consciente.

La inteligencia no sólo lee la interioridad de los seres sino también la propia interioridad, y tal vez es su lectura más importante. No sólo lee sino que se lee, y esta conciencia de su lectura es el primer acto específicamente humano. Cuando la inteligencia lee bien y pronuncia bien su lectura, es decir, cuando dice qué es lo que la cosa es, entonces se realiza el fruto natural de la inteligencia, que es la verdad. A este acto se le llama concepto, que es lo concebido por la inteligencia.

El quehacer ético de la inteligencia consiste en ser buena lectora y concebir buenos conceptos, es decir, que diga de las cosas y de los actos lo que las cosas y los actos son: si convenientes o inconvenientes, si plenifican o mutilan, si favorecen o contrarían el desarrollo, el hacerse humano del hombre. Y cuando la inteligencia hecha conciencia 
es buena lectora y pronuncia su recto veredicto inapelable, la actitud ética consiste en la obediencia a las órdenes de la conciencia. Esto equivale a decir que la actitud ética es la obediencia consciente de las normas que ordenan la realización plena del hombre humano y que se oponen a su segmentación, mutilación, desprecio, menosprecio o distorsión.

Los imperativos categóricos kantianos no son sino expresiones de la razón, de la inteligencia que ve con evidencia el contenido esencial de un acto bueno. "Obra de tal manera que la máxima de tu conducta pueda constituirse en norma universal del buen obrar." La razón no pervertida clama la verdad, bueno es lo justo, lo que se ajusta a las necesidades del hombre humano en el proceso de realización de su proyecto de vida. No puede ser de otra manera: bueno para el hombre es lo que lo hace más pleno, más humano. Y malo es privación, mutilación, bloqueo de humanidad. Éste es el grito de la razón mientras no se pervierte. Por eso la ética es un saber integrador, realizador, liberador del hombre humano, opuesto a las concepciones neuróticas represivas o pseudo libertarias.

La inteligencia cuando lee adecuadamente no engaña al hombre. La inteligencia es luz y da luz, es la mejor consejera del hombre humano. Por eso el ataque a la razón, a la dignidad de la razón ha sido lo más catastrófico y arriesgado que se ha dado en algunas corrientes filosóficas de los últimos 150 años. Menospreciar la razón significa fortalecer la animalitas. Los más graves males de la sociedad moderna no han sido productos de la razón, como dicen algunos críticos de la modernidad, sino agresiones a la razón.

Los dictadores asesinos descarados, de Hitler a Pinochet, incineradores de mujeres, de niños, de ancianos suplicantes, son una agresión a la razón y un monumento a la bestialidad. (¿Que perdonen las bestias!) Las dictaduras de los dictadores disfrazados con votos mercantiles 'democráticos' que imponen su arbitrariedad con las armas compradas con las medicinas de los enfermos, con las camas de los hospitales, con los libros y las mesas de las escuelas, con los salarios de los desempleados y de los explotados, con la felicidad de los ciudadanos; los 
reinos con ciudadanos de papel y de visiones subliminales construidos todos por igual para consumir y ser consumidos, para producir y ser producidos en el sistema de cadenas y de hombres; la globalización de la arbitrariedad que impone su implacable rasero que arrasa con los recursos naturales, culturales, personales, familiares y sociales hasta el logro de la unidimensionalidad inhumana... Todos estos dramas de la sociedad contemporánea ciertamente son mortales agresiones a la razón y sólo podrán corregirse con la obediencia a los mandatos de la razón.

Sin embargo, la inteligencia, que lee y pronuncia la esencia de lo bueno, de lo bello, de lo justo, no hace al hombre bueno, virtuoso y justo. Puede la inteligencia mostrar los caminos de la ética, caminos de realización, que sin embargo pueden ser despreciados. De hecho, el hombre puede conocer lo recto y ser torcido, puede conocer el bien y ser perverso. Han existido innumerables hombres de inteligencia brillante y de conductas malvadas, porque la inteligencia no se comporta como dictadora implacable sino que es respetuosa de la voluntad libre. La inteligencia sólo es implacable e inflexible cuando lee la evidencia de algo y la expresa incorruptiblemente, aunque no sea obedecida.

La calidad ética de una persona no se da por sus conocimientos sino por sus actos, y los actos del hombre humano son construcciones, en última instancia, de la voluntad libre. La personalidad está integrada por la herencia genética, por la influencia del medio y por lo que la persona hace de sí misma por sí misma. Este último elemento es la dimensión ética de la personalidad, y ciertamente la más noble y digna porque es la hechura personal. Esta dimensión es el terreno en el que cada persona debe usar toda su inspiración y originalidad para construir el proyecto arquitectónico único de su propia existencia, que por su singularidad, belleza y diferencia constituye la mayor riqueza humana. (La ética es la gran promotora de estas creaciones humanas porque se propone en primera instancia la realización de las potencialidades del hombre humano.)

Hay proyectos y construcciones brillantes y magníficos, pero predominan los proyectos en serie, hechos a la calca con los rasgos 
que prescriben los poderes irresistibles de las modas, de los gustos, de los modelos de 'éxito'. Son elaboraciones fieles al proceso de clonación 'social'. Estas personalidades producidas así son una ofensa a la ética porque constituyen la fácil entrega a la estructura del molde y la renuncia a la principal obligación ética, que es la responsabilidad de ser humano.

La inteligencia y la voluntad son las potencias maravillosas constructoras de humanidad. La inteligencia, como se ha dicho, ilumina las obscuridades, analiza, juzga, muestra lo conveniente, lo bueno, lo justo, lo verdadero. La inteligencia diseña el proyecto del deber ser de acuerdo a las potencialidades. Pero es la voluntad la que decide, la que ordena, quiere y ama. Se dice que la altura de un hombre se mide por la altura de sus ideas. Esto es cierto si la voluntad decide ascender a la cima de los ideales. Los hombres y mujeres de gran tamaño, que han hundido su huella en la historia han sido hombres y mujeres de firme y poderosa voluntad, de vigoroso carácter.

La voluntad sería mero apetito salvaje o impulso computacional si no fuera por la libertad que la reviste de dignidad y responsabilidad. La moral y la ética no pueden entenderse sin la libertad bien entendida. Es

142 importante repetir que el mérito de un héroe es que pudo ser traidor, el mérito de un gran hombre es que pudo ser mediocre, insignificante, y decidió escalar las alturas de la dignidad personal. Así también la monstruosa maldad moral de un dictador radica en que pudo ser un gobernante respetuoso de la dignidad de los ciudadanos.

La grave inmoralidad de los que abusan de la necesidad del prójimo y lo tratan como mercancía está en que, por supuesto, deben y pueden tratarlo como corresponde a la grandeza natural de un ser humano, tal vez de mayor calidad que la de quienes poseen la abundancia que oprime; la gravedad de las injusticias, de las traiciones y de las violencias se mide por la posibilidad de la justicia, de la fidelidad y del respeto.

Por la libertad el hombre es el único ser en la naturaleza que nace con maravillosas potencialidades y con la tarea y responsabilidad de hacerse, por eso la actividad más importante para cada hombre es 
cumplir muy bien el oficio de ser hombre. Nadie puede encomendar a otro la responsabilidad de inventar y construir su proyecto de vida.

La libertad es una cualidad excelente, sin embargo, el hombre no nace con su carga de libertad al hombro. El inmenso problema de la libertad radica en la posibilidad de ejercerla (libertad positiva). ¿De qué sirve la libertad de elegir el alimento favorito a los miles de millones de personas que no tienen qué comer? ¿De qué les sirve la libertad de elegir a los que no tienen qué vestir, dónde vivir, qué entender, qué carrera elegir, si no tienen casa, vestido, escuela, universidad o proyecto alguno posible? Si es esclavo el que no tiene elecciones posibles, el que está obligado al sometimiento, el que es más hijo de sus circunstancias que de sus padres, el que tiene derecho a ser libre sólo por decreto constitucional, entonces resulta ofensivamente falso que se haya acabado la esclavitud. Por el contrario, hay que afirmar que nunca han existido tantos miles de millones de esclavos como ahora. Tal vez la mayor vergüenza, la mayor ofensa a la ética de la sociedad contemporánea consiste en que los grupos de poder han globalizado la esclavitud, aunque también son esclavos los que están sometidos por la patología de la dominación política, de la hegemonía económica y de la imposición social.

En el ámbito de la ética social no hay desideratum más urgente para la humanidad del hombre humano que procurarle opciones de elección, opciones de libertad. El grito más vehemente de la ética en la presente sociedad es: 'libertad', pero libertad real, con opciones reales. La ética no puede estar presente donde no existe libertad; sólo se aparece para exaltar la grandeza de muchos oprimidos y para juzgar y condenar a los modernos tratantes de esclavos. Porque el acto (ético) pleno de un hombre humano es aquel en el que toman parte activa las potencias más humanas -la inteligencia que lee, ilumina y juzga, la voluntad que elige y la libertad que se hace responsable de la elección- pero sólo cuando existen opciones reales.

La vergonzosa situación del mundo actual es la expresión más opuesta al acto más noble, más digno y más elevado del hombre humano: el amor, invitado de honor de la ética. Es imposible definir 
el amor adecuadamente, porque toda definición es desbordada por su experiencia. El amor es mucho más que cualquier descripción romántica, poética y hasta científica. La falsificación, caricaturización y degradación del amor dificultan más su comprensión. Tal vez la mayor ofensa a la dignidad de este acto humano es su promoción mercantilista: cuando 'te amo' significa te necesito como objeto, como cuerpo o como encanto de satisfacción. En otros términos, el comportamiento refinado del Narciso hedonista predominante en la sociedad de los 'refinados'.

Hay dos condiciones esenciales del amor que por sí solas no dicen lo que es, pero deben estar presentes cuando el verdadero amor está presente: desear sinceramente a quien se ama el bien y procurarlo eficazmente. Puede no existir el agrado sensible, puede incluso existir repugnancia sensible, pero si se desea y se procura el bien, el amor impone su substancia. Por eso es posible amar también al enemigo, que sensiblemente nos repugna. La tan frecuente destrucción de las relaciones humanas profundas, estables, consistentes y hasta maravillosas y heroicas se produce cuando irrumpe el Narciso hedonista, principal protagonista de la moda universal, y cuando se confunde la grandeza del amor humano con la pasión erótica. En estas vivencias se presenta siempre la tensión continua entre humanitas y animalitas.

Otra experiencia indefinible que esconde el hombre humano, es el gozo estético. Una cosa es afirmar que la belleza es unidad en la variedad, equilibrio y vitalidad, y algo muy diferente es la fruición absolutamente indescriptible que produce la contemplación de lo bello.

Todos estos actos difíciles de adjetivar y muchos más que el hombre puede realizar, nos conducen a una apreciación cualitativa singular y diferente. Aristóteles en su psicología afirma (y creo que también en esto sigue teniendo razón), que "las potencias se conocen por sus actos, la naturaleza de las potencias por la naturaleza de sus actos y la naturaleza de los actos por la naturaleza de sus objetos". Sé de la vista por sus visiones, de la inteligencia por sus intelecciones, de la voluntad por sus voliciones. Conozco la calidad de la vista, de la inteli- 
gencia y de la voluntad por la cualidad de las visiones, intelecciones y voliciones. Si pregunto: ¿ve usted su vista? La respuesta será no. Pero tengo certeza de mi vista porque veo y tengo certeza de la calidad o escasez de mi vista por la calidad o escasez de mis visiones. Sobre la inteligencia el razonamiento es más evidente. ¿Existe alguna regla de algún sistema métrico para medir la inteligencia? Ninguna. Pero allí están las pruebas psicométricas, que no son más que ese conjunto de actos que nos dicen: primero, que existe una invisible inteligencia, $\mathrm{y}$ segundo, cuál es la calidad de la inteligencia.

De esta sencilla evidencia se siguen consecuencias inmensas sobre algunas cualidades trascendentes del hombre humano. La idea, como está dicho, es la lectura de la interioridad inmaterial del ser (simple representación intencional de la forma de otro ser); el juicio esencial afirmativo es la identificación de conceptos (dos ideas diferentes terminan siendo idénticas, el amor que ama la inmaterialidad de la verdad; la negación de un impulso sensible por razones abstractas inmateriales (sublimar un impulso sexual por respeto al amor); la reflexión que es la flexión de la inteligencia sobre sí misma siendo ella misma la que piensa y lo que piensa, el pensamiento de su pensamiento, sujeto pensante y objeto pensado (idem). Éstos y muchos otros actos del hombre manifiestan ser cualitativamente diferentes a los actos de los animales, en consecuencia indican una potencia cualitativamente diferente. La diferencia, por tanto, no sólo es cuantitativa (tamaño del cerebro). Pero además, por la inmaterialidad de esos actos y sobre todo por la autosuficiencia de esa parte del entendimiento que a sí mismo entiende y es su entendimiento parece, dice Aristóteles, que esa parte o potencia es una substancia inmortal y eterna.

Estas breves reflexiones sobre lo que hemos llamado el hombre humano parecen suficientes para mostrar que el hombre no es un lobo (Hobbes), ni la cuerda entre la bestia y el superhombre (Nietzsche), ni el único dios adorable (Comte), ni el ser soberano sobre sí mismo, su cuerpo y su espíritu (Mill)... También parece legítimo afirmar que las concepciones éticas derivadas de esas falsas visiones del hombre son igualmente erróneas porque, como se dijo al principio, sólo contestando 
correctamente la pregunta que pregunta sobre el sentido del hombre podemos contestar con certeza y fundamento lo que se debe hacer y lo que se puede esperar.

Desde la perspectiva del hombre humano, hay que decirlo una vez más, la ética es el proceso de realización, de plenificación de ese proyecto maravilloso de humanidad que cada hombre está llamado a vivir con gallardía, con inmensa pasión y dignidad, con decidida libertad, por acosada que acontezca. 